\title{
Violaceae endémicas del Perú
}

Blanca León ${ }^{1,2}$

${ }^{1}$ Museo de Historia Natural, Av. Arenales 1256, Aptdo. 14-0434, Lima 14, Perú

2 Plant Resources Center, University of Texas at Austin, Austin TX 78712 EE.UU

blanca.leon@mail.utexas.edu

\section{Resumen}

La familia Violaceae es reconocida en el Perú por presentar 12 géneros y 61 especies (Brako \& Zarucchi, 1993), entre hierbas, arbustos y árboles. En este trabajo reconocemos 10 especies endémicas en tres géneros. Viola es el género más rico en el número de especies endémicas. La sistemática tanto de la familia, como del género Viola, se hallan bajo estudio, por lo que cambios futuros son de esperarse en su taxonomía. Las especies endémicas reconocidas han sido encontradas principalmente en las regiones Bosques Muy Húmedos Montanos, Mesoandina y Altoandina, entre los 150 y 4600 m de altitud. Se aplicaron las categorías y criterios de la UICN sólo a una especie. Ninguna de las especies se encuentra representada dentro del Sistema Nacional de Áreas Naturales Protegidas por el Estado.

Palabras claves: Violaceae, Viola, Perú, endemismo, plantas endémicas.

\section{Abstract}

The Violaceae are represented in Peru by 12 genera and 61 species (Brako \& Zarucchi, 1993; Ulloa Ulloa et al., 2004), between herbs, shrubs and trees. Here we recognize 10 endemic species in three genera. Viola is the genus with more endemic species. The systematics of both the family and the genus Viola are currently under study, and taxonomic changes and novelties are expected. Endemic species are found mainly in Very Humid Montane Forests, Mesoandean and High-Andean regions, between 150 and $4600 \mathrm{~m}$ elevation. We applied IUCN categories and criteria to only one species. None of the endemic species have been recorded to date within Peru's protected areas system.

Keywords: Violaceae, Viola, Peru, endemism, endemic plants.

\section{Anchietea raimondi Melchior}

\section{DD}

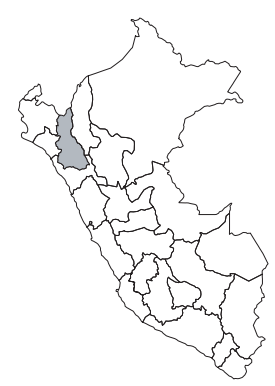

Publicación: Notizbl. Bot. Gart. BerlinDahlem 10: 728-729. 1929

Colección tipo: A. Raimondi 3344

Herbarios: B; USM!

Nombre común: Desconocido.

Registro departamental: CA.

Regiones Ecológicas: BMHM; altitud desconocida.

SINANPE: Sin registro

Herbarios peruanos: USM (isotipo+4).

Observaciones: Liana conocida de una localidad en Cajamarca, al parecer, no ha vuelto a ser recolectada desde el siglo XIX. Esta especie fue descrita de colecciones realizadas por Antonio Raimondi en una localidad cerca del Parque Nacional Cutervo. Los ejemplares conocidos depositados en el herbario San Marcos fueron recolectados en agosto y se encuentran algunos con frutos. Se desconoce el estado de sus poblaciones.

\section{Gloeospermum pilosum Melchior}

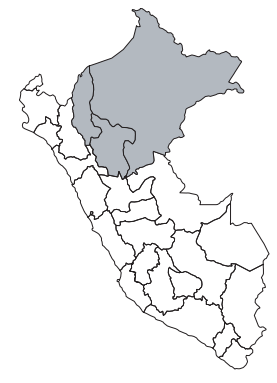

Publicación: Notizbl. Bot. Gart. BerlinDahlem 8: 623. 1923.

Colección tipo: J. Tafalla 1798

Herbarios: B.

Nombre común: Desconocido.

Registro departamental: AM, LO, SM.

Regiones Ecológicas: BMHM, BHA; $150-2300 \mathrm{~m}$

SINANPE: Sin registro.

Herbarios peruanos: Ninguno.
Observaciones: Este taxón fue considerado por Brako \& Zarucchi (1993) como un endemismo; sin embargo, no ha sido posible evaluarlo, ni asignarle una categoría.

\section{Viola hillii W. Becker}

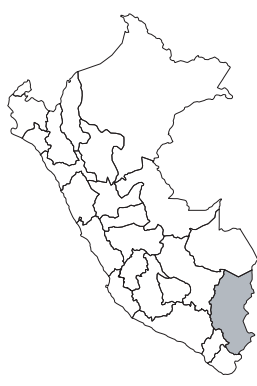

Publicación: Bull. Misc. Inform. Kew 1928: 134. 1928.

Colección tipo: Hill 28

Herbarios:

Nombre común: Desconocido.

Registro departamental: PU.

Regiones Ecológicas: Sin datos; altitud desconocida.

SINANPE: Sin registro.

Herbarios peruanos: Ninguno.

Observaciones: Este taxón fue considerado por Brako \& Zarucchi (1993) como un endemismo; sin embargo, no ha sido posible evaluarlo, ni asignarle una categoría.

\section{Viola huanucoensis W. Becker}

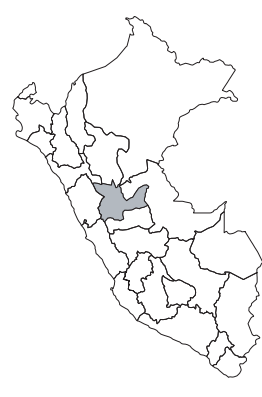

Publicación: Repert. Spec. Nov. Regni Veg. 18: 186. 1922.

Colección tipo: A. Weberbauer 3715

Herbarios: MOL!

Nombre común: Desconocido.

Registro departamental: HU.

Regiones Ecológicas: BMHM; 2000$2300 \mathrm{~m}$.

SINANPE: Sin registro.

Herbarios peruanos: MOL (isotipo). 
Observaciones: Este taxón fue considerado por Brako \& Zarucchi (1993) como un endemismo; sin embargo, no ha sido posible evaluarlo, ni asignarle una categoría.

\section{Viola kermesina W. Becker}

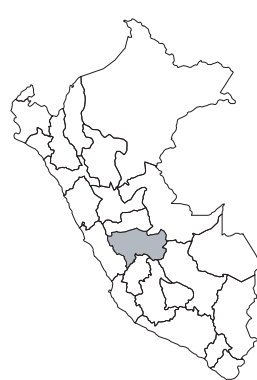

Publicación: Repert. Spec. Nov. Regni Veg. 7: 124. 1909 .

Colección tipo: A. Weberbauer 330

Herbarios: B.

Nombre común: Desconocido.

Registro departamental: JU.

Regiones Ecológicas: AA; $4600 \mathrm{~m}$.

SINANPE: Sin registro.

Herbarios peruanos: Ninguno.

Observaciones: Este taxón fue considerado por Brako \& Zarucchi (1993) como un endemismo; sin embargo, no ha sido posible evaluarlo, ni asignarle una categoría.

\section{Viola membranacea W. Becker}

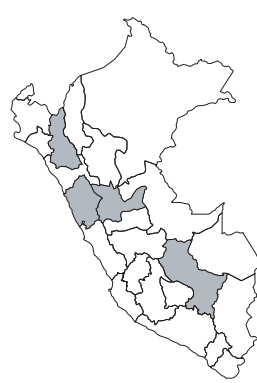

Publicación: Repert. Spec. Nov. Regni Veg. 7: 123.1909.

Colección tipo: A. Weberbauer 347

Herbarios: B.

Nombre común: Desconocido.

Registro departamental: AN, CA, CU, HU.

Regiones Ecológicas: PSH, PAR, AA; 4000—4600 m.

SINANPE: Sin registro

Herbarios peruanos: Ninguno,

Observaciones: Este taxón fue considerado por Brako \& Zarucchi (1993) como un endemismo; sin embargo, no ha sido posible evaluarlo, ni asignarle una categoría.

\section{Viola nobilis W. Becker}

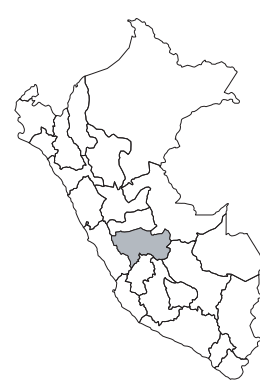

Publicación: Bot. Jahrb. Syst. 37: 590. 1906.

Colección tipo: A. Weberbauer 2214

Herbarios: B; MOL!.

Nombre común: Desconocido.

Registro departamental: JU.

Regiones Ecológicas: MA; 3200 m.

SINANPE: Sin registro.

Herbarios peruanos: MOL (isotipo).

Observaciones: Este taxón fue considerado por Brako \& Zarucchi (1993) como un endemismo; sin embargo, no ha sido posible evaluarlo, ni asignarle una categoría.

\section{Viola pallascaensis W. Becker}

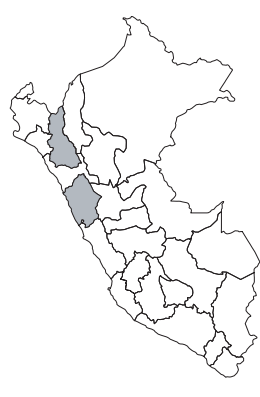

Publicación: Repert. Spec. Nov. Regni Veg. 18: 181. 1922.

Colección tipo: A. Weberbauer 7200

Herbarios: B.

Nombre común: Desconocido.

Registro departamental: AN, CA.

Regiones Ecológicas: PAR; 3560—3800 $\mathrm{m}$.

SINANPE: Sin registro.

Herbarios peruanos: CPUN (5).

Observaciones: Este taxón fue considerado por Brako \& Zarucchi (1993) como un endemismo; sin embargo, no ha sido posible evaluarlo, ni asignarle una categoría.

\section{Viola replicata W. Becker}

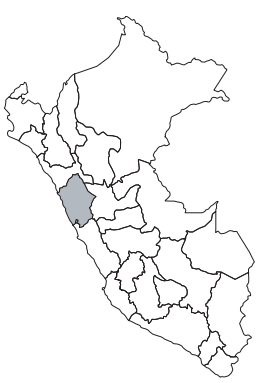

Publicación: Bot. Jahrb. Syst. 37: 589. 1906.

Colección tipo: A. Weberbauer 2961

Herbarios: B; MOL!

Nombre común: Desconocido.

Registro departamental: AN.

Regiones Ecológicas: AA; $4500 \mathrm{~m}$.

SINANPE: Sin registro.

Herbarios peruanos: MOL (isotipo).

Observaciones: Este taxón fue considerado por Brako \& Zarucchi (1993) como un endemismo; sin embargo, no ha sido posible evaluarlo, ni asignarle una categoría.

\section{Viola saccata Melchior}

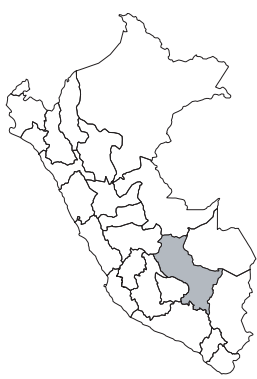

Publicación: Repert. Spec. Nov. Regni Veg. 28: 96-97. 1930.

Colección tipo: A. Weberbauer 7780

Herbarios: B, US.

Nombre común: Desconocido.

Registro departamental: CU.

Regiones Ecológicas: MA; 3100—3200

m.

SINANPE: Sin registro.

Herbarios peruanos: Ninguno.

Observaciones: Este taxón fue considerado por Brako \& Zarucchi (1993) como un endemismo; sin embargo, no ha sido posible evaluarlo, ni asignarle una categoría. 